\title{
Evaluating Brownfield Redevelopment using an Modified Multilevel Grey Method - A Case Study of Xi'an
}

\author{
Yanhua Liang ${ }^{1 *}$, Jie Wei ${ }^{1}$, Hongjuan Lu ${ }^{1}$, Li Zhang ${ }^{1}$ \\ ${ }^{1}$ Management School, Hangzhou Dianzi University, Hangzhou, CHINA
}

Received 28 June 2017 • Revised 15 September 2017 • Accepted 23 September 2017

\begin{abstract}
A novel multiple criteria decision analysis (MCDA) method is designed for comparing and ranking resolution solutions to a brownfield redevelopment project. In particular, an MCDA technique called the modified multilevel grey evaluation method is developed using concepts from grey systems theory, entropy and the analytical hierarchical process (AHP). To obtain weights for the range of criteria and sub-criteria used to assess and compare the resolution solutions, results obtained using AHP and an entropy technique are combined. In order to reflect uncertainty in the evaluation scores of the resolutions according to the sub-criteria, a grey systems class is employed to appropriately transform the scores. Subsequently, the evaluation method for the resolutions along with the combined weights is used to rank the resolutions. To demonstrate how this new methodology can be conveniently used in practice and provide valuable insights for aiding decision making, it is applied to a brownfield site in Xi'an, China, created by a former chemical factory.
\end{abstract}

Keywords: brownfield redevelopment, modified multilevel grey evaluation, grey class, combined weight

\section{INTRODUCTION}

In April 2016, with the widely report of CCTV and many other media on the Changzhou "poison" incident in China, the region's students health injury has become the focus of public attention, which would gradually be concerned about redevelopment of polluted land in city. Brownfield, the opposite of greenfield, refers to a developed property that is abandoned or underutilized. Brownfields usually occur when an industrialized region evolves into a more service-oriented economy. In the United States, the Environmental Protection Agency (US EPA) (2005) defines brownfield sites as "real property, the expansion, redevelopment, or reuse of which may be complicated by the presence or potential presence of a hazardous substance, or contaminant". Brownfields are of widespread concern because they pose serious environmental and public health risks, limit economic development opportunities and restrict urban revitalization. There exists a large number of brownfields in industrialized countries around the world. For example, the USA has between half a million and one million brownfields while Germany is believed to contain about 362,000 sites (Bush, 2002, NRTEE, 2003).

The brownfield redevelopment process consists of re-mediating a given site by treating, removing or isolating the pollutants and subsequently developing the location for useful purposes, such as constructing an office building or creating a new park (G. Atkinson et al.,2014). This procedure usually involves negotiations among a range of stakeholders who attempt to meet, as much as possible, their particular objectives. Brownfield redevelopment has become an important issue in developed countries and benefits society in many ways. It revitalizes urban communities and improves environmental quality. Moreover, a 2003 survey by the US Conference of Mayors demonstrated that brownfield redevelopment in 148 cities could generate 576,373 new jobs and as much as $\$ 1.9$ billion annually in additional tax revenues (US Conference of Mayors, 2003). Brownfield redevelopment also indirectly preserves up to 4.5 hectares of green space for every hectare redeveloped, largely through reduced requirements for new infrastructure and denser site plans, as reported in a George Washington University study (Deason et al., 2011; Mathey et al.,2015). 


\section{Contribution of this paper to the literature}

- The buildup index system for brownfield redevelopment is obtained from six dimensions: environmental and health, financial and accounting, characteristics of the brownfield, social stability, policy and technology criteria, and performance criteria (Zhu \& Guo, 2014).

- The weights can not only balance the roles of the subjective and objective weighting methods, but also almost overcome the one-sidedness of only using one of the two methods (Liang, 2014). Therefore, the weights of the combination weighting method can reflect both the decision makers' subjective intentions and the objective reality, and make our synthetic evaluation results match the actual situation better (Fu \& Zou, 2007).

- The case study indicates that can provide a useful tool for the complicated multiple objective decisionmaking in order to obtain scientific and reasonable results for decision makers (Zhang \& Nie, 2012).

Thus, brownfields have recently received significant attention from governments, communities, environmental advocates, scientists, and researchers around the world. Considerable research has focused on various brownfield redevelopment topics including development of remediation technologies, environmental evaluation, risk assessment and management, financial arrangements, and public involvement (Li \& Chao, 2007). Many methodologies from fields such as economics, systems engineering and management science have been applied to challenging environmental management problems. Among these methodologies, project evaluation methods can be especially valuable to decision makers and stakeholders. For example, a number of optimization models have been developed for evaluating resolutions to environmental problems, such as a linear programming (Lynn et al., 1962), dynamic programming (Evenson et al., 1969; Chia \& Defilippi, 2009), nonlinear programming and conflict resolution models (Rossman, 1980; Hipel \& Bernath, 2011). However, the inherent uncertainty and complexity of selecting the optimal resolution were rarely taken into account.

Grey systems theory developed by Deng (1982) has been widely applied to a range of problems arising in different fields (Lin et al., 2006). It has been shown to be effective for dealing with unquantifiable information, nonobtainable information, incomplete information and partial ignorance (Xia et al.,2015). The grey evaluation method (GEM) is a part of grey systems theory, which is useful for solving problems with complicated interrelationships between multiple factors and variables in the face of high uncertainty. The Analytic Hierarchy Process (AHP) is a multiple objective decision-making method, proposed by the famous American researcher Saaty (1980). AHP serves as a systematic, transparent, and reproducible method for formally modeling and analyzing complex decisions (Chang \& Wang, 2016). The integration of AHP and GEM can be used to solve inexact problems containing multiple criteria and uncertainty in typical decision-making processes. However, only a few studies regarding this integration have been reported in the literature. For example, Chen \& Li (2006) designed a model using AHP and GEM to evaluate the risk of enterprise technological innovation. Wang \& Li (2008) analyzed the choice of third party logistics service agents using a mufti-hierarchical grey evaluation approach. The Modified grey evaluation method proposed by Zhang \& Nie (2012) has been successfully applied to the selection of cooperative partners for virtual enterprises. Because of the mufti-objective and uncertain properties in selecting an optimal brownfield redevelopment resolution, the authors of this paper intend to develop a new modified grey evaluation method for facilitating the decision-making process (Tian et al., 2012; Hsin \& Chen, 2015). The modified approach possesses the advantages of both AHP and GEM, and it is applied to an actual brownfield redevelopment project for verification and demonstration.

\section{THE EVALUATING CRITERION SYSTEM OF BROWNFIELD REDEVELOPMENT}

Evaluation work normally starts with the establishment of evaluation index system. Creation of a criterion system for the evaluation of a brownfield redevelopment project is an important task of the project evaluationbased research framework ( $\mathrm{Zhu}, 2008$; Hsueh \& Su, 2016). Brownfield literature provides numerous studies regarding the reduction of pollution and financial supports, a few of them aimed at setting up an evaluating criterion system for brownfield redevelopment projects. For example, Syms (1999) has proposed six groups of decision-making factors relevant to the redevelopment of brownfields; De Sousa (2000) has developed an index system based on the three aspects of environmental benefits, social benefits and economic benefits; Lange \& McNeil $(2004 a, b)$ have conducted significant research into both the attributes of successful brownfield redevelopments and possible predictors of successful projects; Bacot \& O'Dell (2006) have also suggested practical, valid criteria to measure the viability of governmental brownfield programs in terms of environmental and economic concerns; and Wedding (2007) has proposed an index system to assess the success of redevelopments according to sustainability goals, including multi-stakeholder perspectives, green building elements, and site-level details.

Taking the characteristics of the brownfields of China (Zhu, 2014; Liang, 2014) and the requirements of sustainable development into account, 500 questionnaires were sent to major stakeholders of brownfield 
Table 1. The index system of brownfield redevelopment projects

\begin{tabular}{|c|c|}
\hline Main criteria & Sub-criteria \\
\hline $\begin{array}{l}\text { Environmental and } \\
\text { health benefits } \\
\text { Criteria } B_{1}\end{array}$ & $\begin{array}{l}\text { 1) Improvement of the quality of underground water } B_{11} \\
\text { 2) Improvement of soil quality } B_{12} \\
\text { 3) Improvement of air quality } B_{13} \\
\text { 4) Lowering the health risks of local residents } B_{14} \\
\text { 5) Increase of green cover percentage } B_{15} \\
\text { 6) Improvement of remediation technologies } B_{16}\end{array}$ \\
\hline Financial criteria $B_{2}$ & $\begin{array}{l}\text { 1) Payback period } B_{21} \\
\text { 2) Return on investment } B_{22} \\
\text { 3) Total cost of brownfield redevelopment } B_{23} \\
\text { 4) Ratio of remediation cost to total cost } B_{24} \\
\text { 5) Net present value } B_{25}\end{array}$ \\
\hline $\begin{array}{l}\text { Brownfield site criteria } \\
B_{3}\end{array}$ & $\begin{array}{l}\text { 1) Location of brownfield } B_{31} \\
\text { 2) Status of infrastructure facilities of area } B_{32} \\
\text { 3) Transportation convenience of brownfield area } B_{33} \\
\text { 4) Size of brownfield } B_{34}\end{array}$ \\
\hline $\begin{array}{l}\text { Societal stability } \\
\text { criteria } B_{4}\end{array}$ & $\begin{array}{l}\text { 1) Increase local tax base } B_{41} \\
\text { 2) Increase local employment rate } B_{42} \\
\text { 3) Improvement of local security status } B_{43}\end{array}$ \\
\hline $\begin{array}{l}\text { Policy and technical } \\
\text { criteria } B_{5}\end{array}$ & $\begin{array}{l}\text { 1) Protecting and recycling the land/soil resource } B_{51} \\
\text { 2) Influence from other contamination hazards nearby } B_{52} \\
\text { 3) Difficulty and cycle of remediation } B_{53}\end{array}$ \\
\hline $\begin{array}{l}\text { Performance criteria } \\
B_{6}\end{array}$ & $\begin{array}{l}\text { 1) Matchup with city planning } B_{61} \\
\text { 2) Increase land value of neighborhood } B_{62} \\
\text { 3) Improvement of image of local community and government } B_{63}\end{array}$ \\
\hline
\end{tabular}

redevelopment, which included relevant government divisions, brownfield owners, brownfield developers, the financial sector, public representatives and some other stakeholders. The data collected from the questionnaires are analyzed with the help of factor analysis. Criteria for the brownfield index system are based on the six dimensions (Zhu \& Guo, 2014) given below:

(1) Environmental and health, which focus on the environmental improvement of the area and the health improvement of the communities, mainly from the perspective of soil quality, air quality, groundwater, green ratio, remediation technologies and lowering health risks;

(2) Financial and accounting, which concentrate on the cash flow, development potential and profitability of the brownfield redevelopment project, mainly from the perspective of net present value, rate of return, investment return period, and total cost of the remediation and construction of the brownfield project;

(3) Characteristics of the brownfield, which center on the geographical position of the brownfield, mainly from the perspective of infrastructure facilities, transportation convenience and size of the brownfield;

(4) Social stability, which focuses on enhancing the government's image and the social benefits of redevelopment, mainly from the perspective of increasing local employment rate, increasing local tax base and local security status;

(5) Policy and technology criteria, which concentrate on difficulties in the treatment and the policy support of the redevelopment, mainly from the perspective of protecting and recycling land resources, influences from other nearby contamination hazards, and difficulty and cycle of remediation;

(6) Performance criteria, which focus on the actual practical impacts of brownfield redevelopment, mainly from the perspective of city planning, increasing the land value of the neighborhood, and improving of the image of the local community and government.

A total of 24 criteria are selected for building up the index system from the above-mentioned six dimensions. The evaluating criteria system is shown in Table $\mathbf{1}$.

\section{MODIFIED GREY EVALUATION METHOD}

The AHP organizes the decision-making problem as a hierarchical structure containing several levels. The main criteria define the main goal of the decision problem, and the sub-criteria usually describe the decision resolutions. In order to take into account the uncertainty in brownfield redevelopment and relevant criteria for assessing alternative solutions using AHP (National Research Council, 2005), a modified multilevel grey evaluation approach combining AHP and the grey system method is proposed. 
A three-level hierarchy that represents a standard decision problem with a finite set of resolutions may be considered: B denotes overall objection, $B_{i}(i=1,2, \cdots, m)$ denotes main criterion, $B_{i j}\left(j=1,2, \cdots, n_{i}\right)$ denotes subcriterion, $n_{i}$ denotes the number of sub-criteria corresponding to $B_{i}, k(k=1,2, \ldots, q)$ denotes the serial number of resolutions, $U^{k}$ denotes the comprehensive evaluating value of the $k^{\text {th }}$ resolution.

\section{Constructing the Judgment Matrix Using the Marking Scores}

Index of evaluation is uniformly divided into the following five-scale standard: 5-Excellent, 4-Very Good, 3Fair, 2-Poor, 1-Very Poor. In addition, any level in between two adjacent grades will be awarded the corresponding point scores of $4.5,3.5,2.5$ and 1.5 .

The identification label for an expert is written as $h(h=1,2, \cdots p)$, for which there is a total of $p$ experts. These experts will evaluate or mark resolutions according to the data of criterion $B_{i j}$.

According to the $B_{i j}$ mark of the $k^{\text {th }}$ resolution given by the $h^{\text {th }}$ expert, the judgment matrix $D_{k}$ is obtained:

$$
D_{k}=\left[\begin{array}{llllll}
d_{11}^{1} & d_{11}^{2} & \cdots & d_{11}^{h} & \cdots & d_{11}^{p} \\
d_{12}^{1} & d_{12}^{2} & \cdots & d_{12}^{h} & \cdots & d_{12}^{p} \\
d_{i j}^{1} & d_{i j}^{2} & \cdots & d_{i j}^{h} & \cdots & d_{i j}^{p} \\
d_{m n_{m}}^{1} & d_{m n_{m}}^{2} & \cdots & d_{m n_{m}}^{h} & \cdots & d_{m n_{m}}^{p}
\end{array}\right],
$$

$d_{i j}^{h}$ denotes the mark of the $h^{\text {th }}$ expert with respect to criterion $B_{i j}$.

\section{Combined Weighting Method}

The weights of evaluating criteria have deep effects on the results during the process of quantitative project assessment. If the subjective weighting method is used, the results are often subjective though they can reflect the intentions of decision makers. On the contrary, if only the objective weighting method is used, the results cannot reflect the experience and judgment of decision makers, but may involve a quagmire of mechanical materialism as they have a strong mathematical theory basis. Hence, integrating the two methods may be considered so that the results are more scientific and rational. The combined weighting method used in this paper integrates the AHP, which stands for the subjective weighting method, and the entropy method, which stands for the objective weighting method, in order to evaluate the brownfield redevelopment project (Fu \& Zou, 2007). The steps of the combined weighting method in determining the weights are as follows:

\section{AHP}

The Analytic Hierarchy Process (AHP) is a powerful tool for the analysis of complex decision-making problems. The decision maker expresses his/her preferences by comparing the importance of the elements of the given level with respect to an element of the preceding level. A matrix according to the expert scoring method can be considered and the consistency test be carried out.

The weights of vector a may be given as vector $\alpha=\left(\alpha_{11}, \alpha_{12}, \ldots, \alpha_{i j}, \ldots, \alpha_{m n_{m}}\right)$. The steps of AHP are unnecessary to describe because it is widely used.

\section{Entropy method}

The entropy method is a weight determining method that uses the original data of the criteria of resolutions. The entropy value reflects the degree of disorder in information theory, and can be used to measure the amount of information. The entropy method procedures used to determine the weights are presented as follows:

\section{1) Normalization of the original evaluating matrix}

The $k^{\text {th }}$ resolution can be expressed as $M^{i}=\left[x_{i j}^{k}\right]_{n_{i} \times q}$. Normalization of this matrix produces $Y=\left(y_{i j}^{k}\right)_{n_{i} \times q}$, where $y_{i j}^{c}$ is the data of the $k^{\text {th }}$ evaluating object on the criterion $B_{i j}$. For the criteria for which a larger amount of data is preferred, the function is as follows:

$$
y_{i j}^{k}=\frac{x_{i j}^{k}}{\sum_{k=1}^{q} x_{i j}^{k}}
$$

For the criteria for which fewer data are preferred, the function is as follows: 


$$
y_{i j}^{k}=\frac{1 / x_{i j}^{k}}{\sum_{k=1}^{q}\left(1 / x_{i j}^{k}\right)}
$$

2) Definition of the entropy

$$
e_{i j}=-\lambda \sum_{c=1}^{q} y_{i j}^{c} \ln y_{i j}^{c}
$$

$\lambda=1 / \ln q$, and when $y_{i j}^{k}=0, y_{i j}^{k} \ln y_{i j}^{k}=0$ is supposed.

\section{3) Definition of the weight of entropy}

The weight vector of criterion $B_{i j}$ is $\beta=\left(\beta_{11}, \beta_{12}, \ldots, \beta_{i j}, \ldots, \beta_{m n_{m}}\right)$. The weight value of criterion $B_{i j}$ could be defined as:

$$
\beta_{i j}=\frac{1-u_{i j}}{\sum_{j=1}^{n_{i}}\left(1-u_{i j}\right)}
$$

\section{Combined weighting method}

The combined weighting method is a weight determining method that integrates the subjective and objective weighting methods and reflects information in both methods. So, on the basis of comprehensive analysis of the AHP and the entropy method, the analytic results of the two methods can be combined. The multiplication integration method is used to determine the combined weight $\omega_{i j}$ and can obtain $\omega_{i}=\left(\omega_{i 1}, \omega_{i 2}, \ldots, \omega_{i n_{i}}\right)$.

Multiplication integration method:

$$
\omega_{i j}=\frac{\alpha_{i j} \times \beta_{i j}}{\sum_{j=1}^{n_{i}} \alpha_{i j} \times \beta_{i j}}
$$

As described above, the combined weight $\omega_{i}$ of criterion $B_{i}$ is similarly calculated and is obtained as: $\omega=$ $\left(\omega_{1}, \omega_{2}, \ldots, \omega_{m}\right)$.

\section{Determination of Evaluation Whitenization Weight Function}

Determining the evaluation whitenization weight function means determining the differentiation vector of the grey evaluation class, grey number and grey whiteness function. According to the index set and the marking criteria for assessing the potential resolutions, five evaluation grey classes are used in this case, for which the grey class serial numbers $e, e=1,2,3,4,5$. The numbers denote greatly contribute, comparatively contribute, slightly contribute, no effect and hinder, respectively (Tao \& Song, 2010). The grey class and the corresponding grey whiteness function are as follows:

The first grey class: greatly contribute $(e=1)$, grey number $\bigotimes_{1} \in[5, \infty]$, the corresponding grey whiteness function $f_{1}$ is:

$$
f_{1}=\left\{\begin{array}{ll}
d_{i j}^{h} / 5 & d_{i j}^{h} \in[0,5] \\
1 & d_{i j}^{h} \in[5, \infty] \\
0 & d_{i j}^{h} \notin[0, \infty]
\end{array}\right]
$$

The second grey class: comparatively contribute $(e=2)$, grey number $\bigotimes_{2} \in[0,4,8]$, the corresponding grey whiteness function $f_{2}$ is:

$$
f_{2}=\left\{\begin{array}{ll}
d_{i j}^{h} / 4 & d_{i j}^{h} \in[0,4] \\
\frac{8-d_{i j}^{h}}{4} & d_{i j}^{h} \in[4,8] \\
0 & d_{i j}^{h} \notin[0,8]
\end{array}\right]
$$

The third grey class: slightly contribute $(e=3)$, grey number $\bigotimes_{3} \in[0,3,6]$, the corresponding grey whiteness function $f_{3}$ is:

$$
f_{3}=\left\{\begin{array}{ll}
d_{i j}^{h} / 3 & d_{i j}^{h} \in[0,3] \\
\frac{6-d_{i j}^{h}}{3} & d_{i j}^{h} \in[3,6] \\
0 & d_{i j}^{h} \notin[0,6]
\end{array}\right]
$$
is:

The fourth grey class: no effect $(e=4)$, grey number $\otimes_{4} \in[0,2,4]$, the corresponding grey whiteness function $f_{4}$ 


$$
f_{4}=\left\{\begin{array}{ll}
d_{i j}^{h} / 2 & d_{i j}^{h} \in[0,2] \\
\frac{4-d_{i j}^{h}}{2} & d_{i j}^{h} \in[2,4] \\
0 & d_{i j}^{h} \notin[0,4]
\end{array}\right]
$$

The fifth grey class: hinder $(e=5)$, grey number $\otimes_{5} \in[0,1,2]$, the corresponding grey whiteness function $f_{5}$ is:

$$
f_{5}=\left\{\begin{array}{ll}
1 & d_{i j}^{h} \in[0,1] \\
2-d_{i j}^{h} & d_{i j}^{h} \in[1,2] \\
0 & d_{i j}^{h} \notin[0,2]
\end{array}\right]
$$

\section{Calculating Grey Evaluation Coefficient and Evaluation Matrix}

For evaluation criterion $B_{i j}$, the grey evaluation coefficient of the $k^{\text {th }}$ resolution that belongs to the $e^{\text {th }}$ grey class is written as $x_{i j e}^{k}$, the calculating formulae are:

$$
x_{i j e}^{k}=\sum_{h=1}^{e} f_{e}\left(d_{i j}^{h}\right) \quad x_{i j}^{k}=\sum_{e=1}^{5} x_{i j e}^{k}
$$

For evaluation of criterion $B_{i j}$, the $e^{\text {th }}$ grey evaluation weight of the $k^{\text {th }}$ resolution is written as $r_{i j e}^{k}$, the calculating formula is $r_{i j e}^{k}=\frac{x_{i j e}^{k}}{x_{i j}^{k}}$

The number of grey evaluation class is 5 , the grey evaluation weight vector of criterion $B_{i j}$ for the $k$ th resolution is written as $r_{i j}^{k}, r_{i j}^{k}=\left(r_{i j 1}^{k}, r_{i j 2}^{k}, r_{i j 3}^{k}, r_{i j 4}^{k}, r_{i j 5}^{k}\right)$

According to the grey evaluation weight vector of criterion $B_{i j}$, the grey evaluation matrix $R_{i}^{k}$ of criterion $B_{i}$ for the $k^{\text {th }}$ resolution is obtained as:

$$
r_{i}^{k}=\left[\begin{array}{l}
r_{i 1}^{k} \\
r_{i 2}^{k} \\
\vdots \\
r_{i j}^{k}
\end{array}\right]=\left[\begin{array}{lllll}
r_{i 11}^{k} & r_{i 12}^{k} & r_{i 13}^{k} & r_{i 14}^{k} & r_{i 15}^{k} \\
r_{i 21}^{k} & r_{i 22}^{k} & r_{i 23}^{k} & r_{i 24}^{k} & r_{i 25}^{k} \\
\vdots & & \cdots & & \vdots \\
r_{i i_{i} 1}^{k} & r_{i n_{i} 2}^{k} & r_{i n_{i} 3}^{k} & r_{i n_{i} 4}^{k} & r_{i n_{i} 5}^{k}
\end{array}\right]
$$

\section{The Comprehensive Evaluation of Criterion $\boldsymbol{B}_{\boldsymbol{i}}$}

Assuming the comprehensive evaluation value of criterion $B_{i}$ for the $k^{\text {th }}$ resolution is $A_{i}^{k}$,

$$
\begin{gathered}
A_{i}^{k}=\omega R_{i}^{k}=\left(a_{11}^{k}, a_{12}^{k}, a_{13}^{k}, a_{14}^{k}, a_{15}^{k}\right), \\
A^{K}=\left[\begin{array}{l}
A_{1}^{k} \\
A_{2}^{k} \\
\vdots \\
A_{m}^{k}
\end{array}\right]=\left[\begin{array}{lllll}
a_{11}^{k} & a_{12}^{k} & a_{13}^{k} & a_{14}^{k} & a_{15}^{k} \\
a_{21}^{k} & a_{22}^{k} & a_{23}^{k} & a_{24}^{k} & a_{25}^{k} \\
\vdots & & \cdots & & \vdots \\
a_{m 1}^{k} & a_{m 2}^{k} & a_{m 3}^{k} & a_{m 4}^{k} & a_{m 5}^{k}
\end{array}\right]
\end{gathered}
$$

\section{The Comprehensive Evaluation of Resolutions}

The grey comprehensive evaluation value of the $k_{\text {th }}$ resolution is written as $E^{k}: E^{k}=\omega A^{k}$

According to the differentiation value vector of grey class number $C=(100,80,60,40,20)$, the comprehensive evaluation value of the $k^{\text {th }}$ resolution is written as $U^{k}: U^{k}=E^{k} C^{T}$.

Supposing $U^{k}=\max \left[U^{1}, U^{2}, \cdots, U^{q}\right]$, the $k^{\text {th }}$ resolution is the best resolution for the brownfield redevelopment project.

\section{CASE STUDY}

This paper regards the reformation project of an abandoned chemical plant in Xi'an, China as a case study. The abandoned chemical plant is a contaminated brownfield. With the purpose of promoting economical growth at the brownfield site, the government plans to undertake measures to remedy and redevelop it. There are three redevelopment resolutions for this brownfield: shopping center 1, industrial plant 2, and residential building 3 . Five experts are invited to mark the resolutions according to the marking scheme. The original scores of resolutions 
Table 2. Criteria scores of resolutions by experts

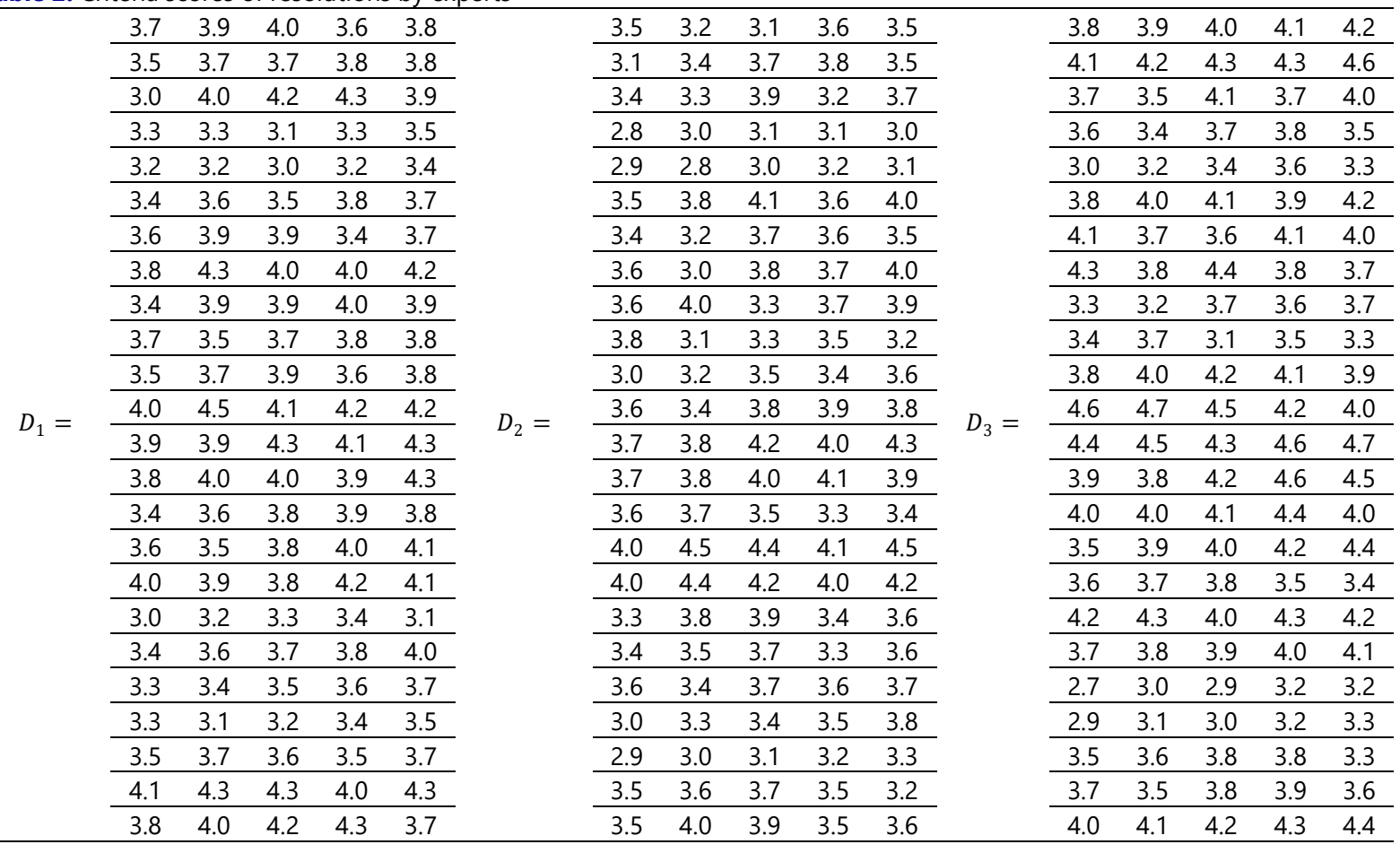

given by the experts are shown in Table 2. Because some qualitative criteria are difficult to quantify, the average scores of criterion given by the experts are treated as the original objective data of resolutions.

The AHP approach is used to determine the subjective weights of different factors in this case. We take into account the experience and wisdom of experts through implementation of the expert scoring method, judgment matrix, sub-level sequencing and consistency test. The subjective weight of criterion $B_{i j}$ is obtained:

$$
\begin{aligned}
& \alpha_{1}=[0.207,0.33 .0 .083,0.235,0.066,0.079], \alpha_{2}=[0.165,0.193,0.099,0.132,0.411], \\
& \alpha_{3}=[0.397,0.199,0.072,0.331], \alpha_{4}=[0.138,0.195,0.667], \alpha_{5}=[0.203,0.644,0.153], \\
& \alpha_{6}=[0.357,0.442,0.201]
\end{aligned}
$$

The objective weights obtained from Eq. (1) to Eq. (4) of the entropy method are as follows:

$$
\begin{aligned}
& \beta_{1}=[0.07,0.07,0.08,0.04,0,39.0 .35], \beta_{2}=[0.17,0.29,0.24,0.15 .0 .15], \beta_{3}=[0.14,0.26,0.46,0.14], \\
& \beta_{4}=[0.69,0.23,0.08], \beta_{5}=[0.67,0.06,0.27], \beta_{6}=[0.22,0.07,0.71]
\end{aligned}
$$

The subjective weights and the objective weights are combined to obtain the combined weights from Eq. (5). The results are as follows:

$$
\begin{aligned}
& \omega_{1}=[0.135,0.216,0.062,0.088,0.242,0.257], \omega_{2}=[0.148,0.296,0.125,0.105,0.326] \\
& \omega_{3}=[0.297,0.277,0.178,0.248], \omega_{4}=[0.493,0.232,0.276], \omega_{5}=[0.63,0.179,0.191] \\
& \omega_{6}=[0.312,0.123,0.566]
\end{aligned}
$$

$\omega$ is obtained in a similar manner: $\omega=[0.277,0.177,0.143,0.064,0.096,0.243]$.

According to Sections 3.6 to 3.8 , the grey evaluating matrix is obtained as follows:

$$
\begin{aligned}
R_{1}^{1} & =\left[\begin{array}{llll}
0.299 & 0.373 & 0.288 & 0.0390 \\
0.286 & 0.358 & 0.297 & 0.0580 \\
0.309 & 0.366 & 0.281 & 0.0430 \\
0.241 & 0.302 & 0.329 & 0.1280 \\
0.231 & 0.288 & 0.337 & 0.1440 \\
0.275 & 0.343 & 0.305 & 0.0760
\end{array}\right], \\
R_{2}^{1} & =\left[\begin{array}{lllll}
0.286 & 0.358 & 0.296 & 0.058 & 0 \\
0.332 & 0.394 & 0.264 & 0.008 & 0 \\
0.301 & 0.377 & 0.286 & 0.035 & 0 \\
0.286 & 0.358 & 0.296 & 0.058 & 0 \\
0.286 & 0.358 & 0.296 & 0.058 & 0
\end{array}\right],
\end{aligned}
$$




$$
\begin{gathered}
R_{3}^{1}=\left[\begin{array}{lllll}
0.351 & 0.397 & 0.251 & 0 & 0 \\
0.337 & 0.393 & 0.261 & 0.008 & 0 \\
0.324 & 0.393 & 0.270 & 0.012 & 0 \\
0.286 & 0.358 & 0.296 & 0.058 & 0
\end{array}\right], \\
R_{4}^{1}=\left[\begin{array}{lllll}
0.298 & 0.369 & 0.288 & 0.043 & 0 \\
0.324 & 0.393 & 0.270 & 0.012 & 0 \\
0.230 & 0.288 & 0.336 & 0.144 & 0
\end{array}\right], \\
R_{5}^{1}=\left[\begin{array}{lllll}
0.286 & 0.358 & 0.296 & 0.058 & 0 \\
0.263 & 0.329 & 0.313 & 0.094 & 0 \\
0.241 & 0.301 & 0.329 & 0.127 & 0
\end{array}\right], \\
R_{6}^{1}=\left[\begin{array}{lllll}
0.274 & 0.343 & 0.305 & 0.076 & 0 \\
0.351 & 0.397 & 0.251 & 0 & 0 \\
0.324 & 0.385 & 0.270 & 0.020 & 0
\end{array}\right], \\
{\left[\begin{array}{l}
\omega_{1} \times R_{1}^{1} \\
\omega_{2} \times R_{2}^{1} \\
\omega_{3} \times R_{3}^{1} \\
\omega_{4} \times R_{4}^{1} \\
\omega_{5} \times R_{5}^{1} \\
\omega_{6} \times R_{6}^{1}
\end{array}\right]=\left[\begin{array}{lllll}
0.269 & 0.335 & 0.309 & 0.086 & 0 \\
0.302 & 0.371 & 0.286 & 0.041 & 0 \\
0.327 & 0.386 & 0.269 & 0.019 & 0 \\
0.286 & 0.353 & 0.297 & 0.064 & 0 \\
0.274 & 0.342 & 0.306 & 0.078 & 0 \\
0.312 & 0.374 & 0.279 & 0.035 & 0
\end{array}\right]}
\end{gathered}
$$

The evaluating results of index criteria can be yielded as follows:

$$
E^{1}=\omega \times A^{1}=\left[\begin{array}{llll}
0.295 & 0.360 & 0.291 & 0.054
\end{array}\right]
$$

Hence the comprehensive evaluating result of the $1^{\text {st }}$ resolution is yielded as follows:

$$
U^{1}=E^{1} C^{T}=77.931
$$

Similarly, the comprehensive evaluating result of the other resolutions is yielded as follows:

$$
U^{2}=75.714, U^{3}=79.898
$$

According to the evaluation results, $U^{3}=\max \left[U^{1}, U^{2}, U^{3}\right]=79.898$, the $3^{\text {rd }}$ is the best resolution for the brownfield redevelopment project.

\section{CONCLUSIONS}

The buildup of the evaluation index system of the brownfield redevelopment project is based on the current situation of brownfields in China and the requirements of sustainable development, and adopts the modified grey evaluation method to prioritize the resolutions for the brownfield redevelopment project. The conclusions and innovations are as follows: 1) Brownfield redevelopment plays a very important role in improving environmental quality and promoting economic growth of the brownfield site. In this paper, the buildup index system for brownfield redevelopment is obtained from six dimensions: environmental and health, financial and accounting, characteristics of the brownfield, social stability, policy and technology criteria, and performance criteria (Zhu \& Guo, 2014); 2) The weights of the combination weighting method obtained from the multiplication integration method are between the values of the AHP and the entropy method. The weights can not only balance the roles of the subjective and objective weighting methods, but also almost overcome the one-sidedness of only using one of the two methods (Liang, 2014). Therefore, the weights of the combination weighting method can reflect both the decision makers' subjective intentions and the objective reality, and make our synthetic evaluation results match the actual situation better (Fu \& Zou, 2007).

Compared to other evaluating techniques, the modified grey evaluation method makes the most use of evaluating information and it avoids yielding invalid evaluating results. The case study indicates that such an approach can provide a useful tool for the complicated multiple objective decision-making in order to obtain scientific and reasonable results for decision makers (Zhang \& Nie, 2012). The disadvantages of this method are that the evaluating matrix is established by the original data of resolutions, and the minor difficulties encountered in obtaining accurate original data of evaluating criteria in application.

\section{ACKNOWLEDGEMENTS}

This work is supported by Humanities and Social Sciences Foundation of Hangzhou Dianzi University (ZX160206304016), Zhejiang Provincial Key Research Base of Humanistic and Social Sciences in Hangzhou Dianzi University (ZX140204304001/009), the Ministry of Education, Humanities and Social Science Youth funded project 13YJC630177, the Research Center of Information, Economic and Social Development of Zhejiang Province funded project 14JDXX03YB. 


\section{REFERENCES}

Atkinson, G., Doick, K. J., Burningham, K., \& France, C. (2014). Brownfield regeneration to greenspace: delivery of project objectives for social and environmental gain. Urban For. Urban Green., 13(3), 586-594.

Bacot, H. (2006). Establishing indicators to evaluate brownfield redevelopment. Economic Development Quarterly, 20(2), 142-161.

Brebbia, C. A. (Eds.) (2006). Brownfields III: Prevention, Assessment, Rehabilitation and Development of Brownfield Sites (Brownfields 2006). Southampton, UK: WIT Press.

Bush, G. W. (2002). Remarks by the President in signing of H.R. 2869, The Small Business Liability Relief and Brownfields Revitalization $\quad$ Act. $\quad$ Retrieved from http://www.whitehouse.gov/news/releases/2002/01/20020111-3.htmlS

Canadian Urban Institute. (2005). The Canadian Urban Institute's Brownfielder Report. Retrieved on 17 February 2005 from http://www.canurb. om/media/pdf/Brownfielder Report_2002.pdf

Chang, T. C., \& Wang, H. (2016). A Multi Criteria Group Decision-making Model for Teacher Evaluation in Higher Education Based on Cloud Model and Decision Tree. Eurasia Journal of Mathematics, Science E Technology Education, 12(5).

Chen, K., \& Li, H. (2006). Risk evaluation for Enterprise' Technology Innovation Based on Grey Hierarchy Method. Systems Engineering - Theory \& Practice, (7), 98-104.

Chia, S. S., \& Defilippi, J. A. (1970). System optimization of waste treatment plant process design. Journal of environmental Engineering Division, ASCE, 96, 409-421.

De Sousa, C. A. (2000). The Brownfield Problem in Urban Canada: Issues, Approaches and Solutions (Doctoral Dissertation).

Deason, J. P., Sherk, G. W., \& Carroll, G. A. (2001). Public Policies and Private Decisions Affecting the Redevelopment of Brownfields: An Analysis of Critical Factors, Relative Weights and Areal Differentials. A report to the US. Washington, DC: EPA.

Deng, J. L. (1987). Essential Topics on Grey System: Theory and Applications. Wuhan: Huazhong University of Science and Technology Press (in Chinese).

Dick, R. I. (1984). Integration of sludge management processes. In Proceedings of the International Symposium on Wastewater Engineering and Management Society of Environmental Science of Guangdong, Guangzhou, People's Republic of China, March 1984.

Dorsey, J. W. (2003). Brownfields and greenfields: the intersection of sustainable development and environmental stewardship. Environmental Practice, (5), 1 March.

Evans, J., Wood, G., \& Miller, A. (2006). The risk assessment-policy gap: An example from the UK contaminated land regime. Environment international, (32), 1066-1071.

Evenson, D. E., Orlob, G. T., \& Monser, J. R. (1969). Preliminary selection of waste treatment systems. Journal of Water Pollution Control Federation, 41, 1845-1858.

$\mathrm{Fu}, \mathrm{X} .$, \& Zou, M. Application of combination weighting method in contract risk's evaluation of third party logistics. Journal of Southeast University, 23, 128 - 132.

Hemphill, L. \& Berry, J. (2004). An indicator-based approach to measuring sustainable urban regeneration performance: part 2, empirical evaluation and case-study analysis. Urban Studies, 41(4), 757-772.

Hipel, K. W., Bernath Walker, S. (2011). Conflict Analysis in Environmental Management, Environmetrics. Wiley Online Library, 22(3), 279-293. doi:10.1002/env.1048

Hsin, P. H., Chen, C. I. (2014). The evolution of grey forecasting and its application on a stock price prediction. Stock Forex Trading, 3(3), 1-2.

Hsueh, S. L., \& Su, F. L. (2016). Critical factors that influence the success of cultivating seed teachers in environmental education. Eurasia Journal of Mathematics, Science E Technology Education, 12(11).

Huang, J. T., \& Liao, Y. S. (2003). Optimization of machining parameters of Wire-EDM bases on grey relation and statistical analysis. International Journal of Production Research, 41, 1707-1720.

Li, S., Guo, Y. J., Yi, P. T., Tian, H. P. (2004). Partner selection based on fuzzy group decision making for virtual enterprise formation. Journal of Northeastern University, 25(3), 295-298.

Lin, C. T., Chang, C. W., \& Chen, C. B. (2006). The worst ill-conditioned silicon wafer machine detected by using grey relational analysis. International Journal of Advanced Manufacturing Technology, 31, 388-395.

Liu, J., \& Li, C. (2007). Generalized evaluation based on AHP/grey theory for product Quality. Journal of Northeastern University, 28(11), 1068-1611. 
Luo, D. (2005). Study on the method for grey incidence decision making. China Journal of Management Science, 13(1), 101-106.

Lynn, W. R., Logan, J. A., \& Charnes, A. (1962). System analysis for planning .wastewater treatment plants. Journal of Water Pollution Control., Federation, 34, 565-581.

Ma, Y. (2000). Selection mothed of cooperated partners in the network alliance enterprise. Journal of Mechanical Engineering, 36(1), 15-19.

Mathey, S. R., Banse, J., Lehmann, I., \& Bräuer, A. (2015). Brownfields as an element of green infrastructure for implementing ecosystem services into urban areas. Urban Plan. Dev., 141(3).

National Research Council. (2005). Decision Making for the Environment: Social and Behavioral Research Priorities. Washington, DC: National Academy Press.

Pagea, G. W. (2006). Characteristics and land use of contaminated brownfield properties in voluntary cleanup agreement programs. Land Use Policy, 23, 551-559.

Rossman, L. A. (1980). Synthesis of waste treatment systems by implicit enumeration. Journal of Water Pollution Control Federation, 52,148-160.

Saaty, T. L. (1980). The analytic Hierarchy Process. New York: McGraw-Hill.

Simons, R. A. (2001). Local government intervention in the brownfield arena. Economic Development Commentary, (25), 12-18.

Sun, S. (2005). Research on decision making method based on gray correlation degree and TOPSIS. Chinese Journal of Management Science, 13(4), 63-68.

Taocheng, S. (2010). Multilevel grey evaluation on the comprehensive contribution of standards to Shanghai automobile industry. Shanghai Univ (Engl Ed), 14(4), 301-305.

Tian, X., Chen, F., \& Chen, Y. (2014). Grey relational analysis on the influence factors of China comprehensive grain production capacity. In 1st International Conference on Industrial Economics and Industrial Security, 387-391.

US EPA. (2005). EPA Brownfields. Retrieved from http://www.epa.gov/brownfields/S

Wang Lixin, L. (2006). Multi-hierarchical grey evaluation on the operation item' choice of the third party logistics service agents. Systems Engineering - Theory \& Practice, 26(1), 97-101.

Wedding, G. C., Crawford-Brown, D. (2007). Measuring site-level success in brownfield redevelopments: A focus on sustainability and green building. Journal of Environmental Management, 85, 483-495.

Xia, X. Q., Govindan, K., \& Zhu, Q. H. (2015). Analyzing internal barriers for auto parts manufacturer in China using Grey-Dematel approach. Journal of Cleaner Prod., 87, 811-825.

Zhang, C., \& Nie, M. (2007). Selection of cooperative partners for virtual enterprises based on modified grey evaluation method. Systems Engineering - Theory E Practice, (11), 54-60.

Zhou, C. (2003). Multiobjective grey relevant optimized decision making model of select vendors and its application. Science \& Technology Progress and Policy, 20(8), 60-62.

Zhu, Y., Hipel, K. W., \& Guo, P. (2008). A Research Framework for Tackling Brownfield Problems in China Using Project Management Theory. 2008 IEEE International Conference on Systems, Man and Cybernetics, Singapore, October 12-15, 2008.

Zhu, Y., Su, H., \& Guo, P. (2009). Factor Analysis Based Buildup of Index System for Evaluation of Brownfield Redevelopment Project. The 2009 International Conference on Engineering Management and Service Sciences, Beijing, September 20-22, 2009.

\section{http://www.ejmste.com}

